\title{
HARMONIZAÇÃO DE REGULAMENTOS E NORMAS TÉCNICAS NO MERCOSUL
}

\author{
Luís Fernando Tironi ${ }^{1}$
}

\begin{abstract}
Com trinta anos de vida, o Mercosul acumulou informações e experiências que devem ser aproveitadas para orientar seu desenvolvimento nas décadas vindouras. Se os resultados podem não ter atendido às mais otimistas expectativas, o Mercosul continuou existindo e mantendo fidelidade aos seus objetivos fundadores: criação de uma área de livre comércio e união aduaneira sub-regional na América do Sul. A experiência acumulada na harmonização de regulamentos e normas técnicas, condição para superar as barreiras técnicas ao comércio e viabilizar a integração produtiva, é bastante grande. Os resultados obtidos em termos de competitividade e comércio poderiam ter sido melhores, mas os desafios foram grandes. A instabilidade macroeconômica, assim como o histórico de infraestruturas pouco convergentes, e as diferenças estruturais entre os parceiros no acordo foram os principais obstáculos. Essencial para a constância de atitudes e ações que se verificou nas três décadas do Mercosul, no tema dos regulamentos e normas técnicas, é a similaridade na colaboração entre o governo e o setor privado nos países integrantes do bloco.
\end{abstract}

Palavras-chave: Mercosul; acordos comerciais; integração produtiva; regulamento técnico; norma técnica; harmonização regulatória.

\section{REGULATORY HARMONIZATION AND TECHNICAL STANDARS IN MERCOSUR}

With thirty years of life, the Mercosur has accumulated information and experiences that should be used to guide its development in the decades to come. If the results may not have met the most optimistic expectations, Mercosur continued to exist and to remain faithful to its founding objectives: the creation of a free trade area and the sub-regional customs union in South America. The accumulated experience in harmonizing regulations and technical standards, a condition for overcoming technical barriers to trade and making productive integration feasible, is quite substantial. The results obtained in terms of competitiveness and trade could have been better, but the challenges were greater. Macroeconomic instability as well as the historically poor infrastructure and structural differences between partners were the main obstacles. The similarity in the government's collaboration with the private sector in the countries that integrate the bloc was essential to the stability of the practices and actions that took place in the three decades of Mercosur, in the area of regulations and technical standards.

Keywords: Mercosur; trade agreements; productive integration; technical regulation; technical standard; regulatory harmonization.

\footnotetext{
1. Técnico de planejamento e pesquisa na Diretoria de Estudos e Relações Econômicas e de Política Internacionais (Dinte) do Ipea; engenheiro mecânico com mestrado em economia; ex-secretário de mecânica de precisão no então Ministério da Ciência e Tecnologia; ex-diretor do Ipea; e ex-representante do Ministério da Economia no Subgrupo de Trabalho (SGT) Indústria (no 7) do Mercado Comum do Sul (Mercosul). Orcid: <http://orcid.org/0000-0003-2964-1066>.
} 


\section{ARMONIZACIÓN DE LOS REGLAMENTOS Y NORMAS TÉCNICAS EN EL MERCOSUR}

Con treinta años de vida, el Mercosur ha acumulado información y experiencias que deberían servir para orientar su desarrollo en los próximos decenios. A pesar de que los resultados no han respondido a las expectativas más optimistas, el Mercosur continúa existiendo y permaneciendo fiel a sus objetivos fundacionales: la creación de una zona de libre comercio y la unión aduanera subregional en América del Sur. La experiencia acumulada en la armonización de reglamentos y normas técnicas, una condición para superar las barreras técnicas al comercio y hacer viable la integración productiva, es bastante grande. Los resultados obtenidos en cuanto a competitividad y comercio podrían haber sido mejores, pero los desafíos eran grandes. La inestabilidad macroeconómica, así como la historia de una infraestructura poco convergente y las diferencias estructurales entre los socios del acuerdo fueron los principales obstáculos. La similitud en la colaboración entre el gobierno y el sector privado en los países que conforman el bloque es esencial para la constancia de las actitudes y acciones ocurridas en las tres décadas del Mercosur, en materia de regulaciones y normas técnicas.

Palabras clave: Mercosur; acuerdos comerciales; integración productiva; reglamento técnico; norma técnica; armonización regulatoria.

JEL: F13; F15.

DOl: http://dx.doi.org/10.38116/rtm23art9

Data de envio do artigo: 6/7/2020; Data de aceite: 24/8/2020.

\section{INTRODUÇÃO}

Aos trinta anos de existência, o Mercosul $^{2}$ tem um longo repertório de iniciativas, açóes e realizaçóes a apresentar. Este trabalho destaca o esforço de harmonização normativa dos regulamentos técnicos e normas técnicas. Tal esforço merece mais atenção dos analistas. Os impactos das instabilidades macroeconômicas e políticas certamente prevaleceram aos olhares dos observadores da performance do bloco sub-regional. Além disso, a harmonização regulatória e a harmonização das normativas técnicas são do âmbito da microeconomia, e como tal são conduzidas nas instâncias da base da estrutura decisória do bloco, de menor visibilidade ao observador, ainda que tenham intensivamente demandado a atenção das instâncias decisórias superiores.

Este texto oferece uma visão em retrospectiva de alguns movimentos marcantes da evolução do bloco na temática da harmonização de regulamentos e normas técnicas. Foi elaborado com base em consultas a documentos oficiais acessáveis por meio eletrônico e na bibliografia que oferece uma visão geral do desenvolvimento do bloco sub-regional. Em que pesem os desafios e dificuldades, o bloco manteve-se fiel aos objetivos originais de construção da área de livre comércio e união aduaneira.

$\mathrm{O}$ aprofundamento da pesquisa junto aos protagonistas nas esferas pública e privada é indispensável para melhor circunstanciar o entendimento dos 
sucessos e dos desafios da harmonização normativa do Mercosul. É indispensável também uma melhor qualificação do papel, dos desafios e das estratégias para a harmonização normativa do bloco a serem seguidas em suas próximas três décadas de vida. Isso se faz necessário para a reafirmação dos objetivos do bloco e ajustes das estratégias para alcançá-los.

As reduçôes das tarifas alfandegárias promovidas por acordos comerciais e por iniciativas unilaterais de países resultaram em uma grande expansão do intercâmbio comercial internacional nas últimas décadas. Concomitantemente, verificou-se a multiplicação das cadeias produtivas internacionais - deste patamar, a continuidade do crescimento do comércio internacional depende em larga medida da remoção das barreiras não tarifárias (BNTs) ao comércio.

As BNTs ao comércio compreendem duas situaçóes. A primeira refere-se às chamadas medidas não tarifárias (MNTs), em geral governamentais, voltadas para a proteção à saúde humana e animal, questôes sanitárias ambientais e outras. Como tais, são aceitáveis, desde que não eivadas de viés protecionista. A segunda compreende a esfera das normas técnicas, de origem eminentemente privada.

As duas situaçóes se entrecruzam quando as MNTs recorrem às normas técnicas para obter o respaldo técnico-científico (support standards). Se não forem justificáveis do ponto de vista técnico-científico, tanto as MNTs como as normas técnicas podem adquirir a conotação de BNTs, as quais podem impor custos de transação importantes ou representar óbices intransponíveis ao comércio internacional.

Estudos indicam que os custos de transação ao comércio internacional representados pelas BNTs podem ser equivalentes aos decorrentes do perfil tarifário remanescente, em termos globais. Em contrapartida, a eliminação das BNTs requer medidas muito diferentes em relação ao phasing out tarifário. Para removê-las, é necessário atuar sobre questōes legais e institucionais internas aos paises (behind the border).

Duas categorias de BNT sobressaem em importância: as barreiras técnicas ao comércio (BTCs) e as barreiras sanitárias e fitossanitárias (sanitary and phytosanitary - SPS). As primeiras, BTCs, são mais relacionadas a produtos industriais. As SPS prevalentemente se referem a alimentos, produtos agrícolas e pecuários. Embora a expressão "barreira técnica ao comércio" possa contemplar as situaçóes pertencentes às duas esferas, BTCs e SPS, a ênfase deste artigo nas normas técnicas realça a conotação industrial das BTCs.

O desprovimento das MNTs da condição de barreiras ao comércio é um tema de crescente importância na governança do comércio internacional. A Organização Mundial do Comércio $(\mathrm{OMC})$ propóe duas linhas de atuação. 
A primeira é o mecanismo de notificação, que cria condiçóes para que um país que se considere prejudicado por medidas interpostas ao comércio sem a adequada justificativa técnico-científica possa recorrer à OMC. A segunda linha de atuação propugnada pelo órgão para eliminar ou reduzir as BTNs é recomendar a adoção e a aplicação de normas técnicas internacionais.

Normas técnicas são essenciais ao comércio, na medida em que definem com precisão científica as características dos bens e dos serviços transacionados. Substituem com vantagem textos que seriam longos e imprecisos, o que as torna de grande utilidade para formulações jurídicas - daí seu frequente emprego nos regulamentos técnicos. Porém, enquanto o emprego das normas técnicas de per si é de caráter voluntário, se incorporadas em regulamentos técnicos emitidos pelo poder público, podem adquirir caráter mandatório.

As normas técnicas são importantes para o comércio, para a divisão do trabalho e a integração produtiva e para as cadeias produtivas. Mas ocorre de poderem ser utilizadas como expediente de protecionismo, por meio de seu emprego como support standards em regulamentos técnicos. A utilização da norma técnica internacional em substituiçâo às normas nacionais contribui para eliminar ou reduzir eventual viés protecionista embutido no regulamento técnico. ${ }^{3}$

A harmonização regulatória é um recurso importante para eliminar as BTCs existentes ou que possam ser criadas. Busca-se a harmonização dos regulamentos técnicos no âmbito de acordos comerciais, plurilaterais, bilaterais, regionais, negociada e implementada durante a negociaçâo do acordo, e instituída na sua vigência. Um princípio da maior importância na busca da eliminação das BTCs no âmbito dos acordos de livre comércio ou de preferências é que os standards regionais desenvolvidos e adotados pelos parceiros do acordo não se tornem também obstáculos ao comércio extrabloco dos países-membros.

A harmonização dos regulamentos técnicos tem-se revelado um formidável desafio para os partícipes dos acordos comerciais. Contribui para essa dificuldade a adoção pretérita de normas técnicas nacionais, mesmo que tenham sido inspiradas ou adaptadas de normas internacionais. Essa dificuldade inclui a avaliaçấo de conformidade, um sobrecusto importante ao comércio. O reconhecimento recíproco de certificados de conformidade já constitui uma modalidade de harmonização regulatória.

3. A OMC recomenda a adoção dos international standards. São considerados pela OMC international standards os desenvolvidos e adotados em organizações como a International Standard Organization (ISO), a International Electrotechnical Commission (IEC) e a International Telecommunication Union (ITU), no âmbito do Acordo sobre Barreiras Técnicas ao Comércio (Agreement on Technical Barriers to Trade - TBT). Standards gerados em outras standard development organizations (SDOs), se atendem ao critério de relevância e efetividade, são considerados também international standards, como é o caso de algumas SDOs norte-americanas geradoras de standards setoriais globais. No âmbito do SPS, é explícita a indicação das SDOs geradoras de standards internacionais, como o Codex Alimentarius, da Food and Agriculture Organization (FAO), a World Health Organization (WHO), entre outras. 
Este artigo desenvolve uma apreciação da temática das BTCs a partir da experiência do Mercosul. Tem seu foco nas dificuldades do bloco para superar barreiras técnicas e nos esforços e iniciativas adotados para superá-las. É enfatizado o papel da norma técnica.

O Mercosul é a experiência mais abrangente e profunda de integração internacional do Brasil e dos demais parceiros do bloco. Seu sucesso ou insucesso, em boa medida, guarda uma relação com dificuldades no campo das barreiras técnicas - ou com a estratégia adotada para superá-las por meio da harmonização regulatória.

São escassas as sistematizaçôes, avaliações, formulações de diagnósticos e também o oferecimento de sugestóes, dos meios governamentais, acadêmicos, empresariais, para o aprimoramento da harmonização dos regulamentos técnicos no Mercosul. Pesquisas recentes examinaram a temática para Brasil e Argentina (Thorstensen et al., 2019; Thorstensen e Tironi, 2019). Espera-se que este artigo contribua para aumentar o interesse pelo aperfeiçoamento da estratégia de abordagem da temática dos regulamentos e normas técnicas no Mercosul.

A finalidade última deste estudo é oferecer indicaçōes de ações que contribuam para uma maior eficácia no esforço de superação das barreiras técnicas à integração sub-regional do Mercosul. Para atender a esse objetivo, além desta introdução, o artigo compóe-se de mais cinco partes: acordos comerciais, regulamentos e normas técnicas; regulamentos e normas técnicas do Mercosul; marcos na harmonização normativa técnica no Mercosul; a Resolução Mercosul/Grupo Mercado Comum (GMC) no 45, de 2017; e as consideraçóes finais (há também um apêndice no final).

\section{ACORDOS COMERCIAIS, REGULAMENTOS, NORMAS TÉCNICAS}

O TBT e o Acordo SPS da OMC estabelecem os conceitos e procedimentos para a mitigação dos efeitos das BTCs sobre o comércio internacional. Uma das proposiçóes da OMC é uso da norma técnica internacional para "nivelar o campo" da disputa comercial na esfera da norma técnica. ${ }^{4}$

$\mathrm{O}$ acordo de preferências comerciais (trade preferential agreement-TPA), ou acordo de livre comércio (free trade agreement - FTA), especialmente se também busca alguma integração produtiva das economias envolvidas, despende grandes

4. A norma técnica é de observância voluntária, sendo em geral desenvolvida por entidades integradas por agentes não governamentais (também os governamentais). É um documento eminentemente técnico-científico. 0 regulamento técnico, que em muitos casos recorre e mesmo incorpora a norma técnica (support standard), é um ato do poder público de observância mandatória. 
esforços no tratamento das questóes normativas e regulatórias. ${ }^{5}$ Processos de liberalização comercial e/ou de integração econômica demandam e, ao mesmo tempo, oferecem possibilidades de superação das barreiras ao comércio decorrentes de divergências regulatórias e normativas das partes envolvidas. ${ }^{6}$

As áreas de saúde, segurança, sanitária são de alta incidência de regulamentos técnicos e é crescente a incidência de regulamentação técnica na área de sustentabilidade ambiental. A necessidade de novas normas técnicas e de regulamentação técnica também responde às necessidades do desenvolvimento, à evolução das necessidades e aspiraçóes sociais e também ao desenvolvimento tecnológico e inovação, como se observa claramente na área de Tecnologia da Informação e Comunicação (TIC).

$\mathrm{Na}$ estrutura do estado há instâncias dedicadas a regulamentos técnicos e normas técnicas. A função é realizada por meio do exercício direto pela estrutura do Estado ou de função delegada do poder público. ${ }^{7}$ Em grande medida, as políticas públicas são embasadas e executadas por regulamentos técnicos e normas técnicas que, nessa perspectiva, se apresentam como interface entre o interesse público e o da sociedade e dos indivíduos.

\section{MERCOSUL: REGULAMENTOS E NORMAS TÉCNICAS}

Aos dez anos de existência, no final da década de 1990 e início da década de 2000, a balança das avaliaçóes sobre as perspectivas de consolidação do Mercosul e atingimento dos objetivos de constituição da área de livre comércio e da união aduaneira tendia para o lado negativo. O bloco passava por uma crise severa e analistas questionavam especialmente a viabilidade da constituição da união

\footnotetext{
5. 0 termo regulatório, ainda que de emprego perfeitamente adequado ao contexto do comércio e dos processos de integração econômica e comercial, tem um alcance que vai além do que se emprega no contexto desta análise, que se cinge ao domínio do chamado regulamento técnico. 0 regulamento técnico responde a necessidades eminentemente internas (behind the border), na esfera das questões de saúde, segurança, sanitárias, ambientais, estratégicas (economicidade de escala e escopo em sistemas produtivos, por exemplo). Se inadequado, pode representar um ônus à sociedade em termos não só de sua finalidade precípua (saúde, segurança, sanitária, ambiental, eficiência) como da produtividade e dos custos que impõe sobre a produção e a circulação de bens e de serviços. Na dimensão internacional, o regulamento técnico é importante, não apenas pelo que representa em termos das suas funções precípuas como pelo que pode representar em termos de facilitação ou de dificuldade às transações e ao comércio.

6. Cita-se Gafa Milan: "A normalização europeia tem um papel importante a desempenhar na remoção dos obstáculos técnicos ao comércio e, portanto, na promoção do desenvolvimento do mercado único da União Europeia. As normas técnicas substituem disposições jurídicas pormenorizadas e simplificam as regras, o que acabará por tornar toda a economia europeia mais competitiva. A definição de requisitos básicos obrigatórios também garantirá um elevado grau de proteção para os consumidores, a saúde e o ambiente. A normalização é indispensável em setores como o dos cuidados de saúde, dos transportes, das telecomunicações ou da engenharia eletrotécnica. No setor dos cuidados de saúde, por exemplo, existem cerca de 10 mil dispositivos médicos diferentes e as normas europeias desempenham um papel regulador importante neste campo. Ao estabelecerem definições pormenorizadas dos requisitos para garantir um elevado nível de segurança do doente, estas normas também promovem a inovação". Disponível em: <https://www. europarl.europa.eu/sides/getDoc.do?pubRef=-//EP//TEXT+CRE+20060516+ITEMS+DOC+XML+V0//PT\#title4>.

7. No Brasil, a atribuição de desenvolver, adotar e gerir as normas técnicas cabe à Associação Brasileira de Normas Técnicas (ABNT), entidade não governamental sem fins lucrativos, por delegação do poder público.
} 
aduaneira. Problemas de ordem econômica e política estavam na base do crescente questionamento sobre o futuro do bloco (Costa, 2001).

As crises macroeconômicas que por essa época acometeram Brasil e Argentina provocaram contenciosos de toda ordem, inclusive nos temas setoriais e microeconômicos. A abrangente estrutura de governança do bloco foi intensamente demandada, especialmente na base da pirâmide de governança, em que se tratam as questôes setoriais e temáticas específicas, como regulamentos e normas técnicas. O modo como isso se processou contribuiu para que os resultados do bloco fossem vistos ou realmente estivessem aquém dos seus objetivos. ${ }^{8}$

A harmonização regulatória é um grande desafio para os acordos comerciais e de integração econômica (especialmente estes) se as estruturas públicas e privadas da Infraestrutura da Qualidade (IQ) e suas institucionalidades forem muito díspares entre as partes. No caso, agrava a situação serem as bases normativas, incluindo o aparato das normas técnicas dos Estados-parte, historicamente dissociadas.

Uma instância de base (a principal) para o tratamento do tema da harmonização regulatória no Mercosul é o SGT Regulamentos Técnicos e Avaliação da Conformidade (no 3), da Comissão de Comércio do Mercosul (CCM). Outros SGTs também têm interveniência em assuntos regulatórios, como os de Agricultura e Saúde. Para esses e outros, também confluem muitas questôes relativas a regulamentos técnicos, normas técnicas, avaliaçâo de conformidade, procedimentos alfandegários etc.

Seguindo a hierarquia decisória do bloco, as decisóes formuladas nos SGTs eram decididas nas instâncias superiores, como o GMC, a instância executiva decisória máxima na estrutura de governança do bloco. De particular interesse para o escopo deste trabalho foi a decisão do GMC acatando a proposta formulada no SGT no 3 e respaldada pela CCM, no final 1990, autorizando o convênio com a Associação Mercosul de Normalização (AMN).

A decisão do GMC autorizando o convênio com a AMN é ilustrativa da atitude de afirmação dos objetivos do bloco adotada pela estrutura de governança do Mercosul num momento de crescimento dos questionamentos sobre o futuro. Outra decisão de forte significado e maior visibilidade foi a criação da instância recursal permanente no mecanismo de solução de controvérsias no bloco. Essas duas iniciativas indicam que a perspectiva dos protagonistas da estrutura de

8. A relativa pouca clareza quanto à contribuição estratégica da harmonização regulatória aos objetivos últimos do bloco sub-regional fazia com que as metas dos grupos de trabalho fossem definidas pelas necessidades, oportunidades e dificuldades mais imediatas. Mudanças nas representações das partes também contribuíram para a visão de curto prazo, ainda que a estrutura dos subgrupos de trabalho (SGTs) fosse perene. Em geral, a representação privada tende a ser mais permanente que a governamental, sujeita às mudanças dos governos nacionais. 
governança se manteve mirando os objetivos maiores de constituição da área de livre comércio e união aduaneira.

Desde 1991, o SGT no 3 do Mercosul levou e ajudou a aprovar, na instância decisória executiva máxima do bloco, o GMC, resoluçốes de sua proposição. Contribui para a amplitude do trabalho do SGT no 3 o seu escopo de atuação "horizontal", pois inclui a metrologia, disciplina comum à atividade de normalização técnica em qualquer atividade. Assim, o SGT no 3 exerce sua função em interatividade com os demais SGTs.

A regulamentação técnica no Mercosul éobjeto também dos SGTs Agricultura (no 8), Indústria (no 7), Transporte (no 5), Energia ( $\mathrm{n}^{\circ}$ 9), Comunicaçốes ( $\mathrm{n}^{\circ}$ 1), Meio Ambiente, Assuntos Trabalhistas, Emprego e Seguridade Social (no 10), Saúde ( $\mathrm{n}^{\circ}$ 11), Comércio Eletrônico ( $\mathrm{n}^{\circ}$ 13), Integração Produtiva ( $\mathrm{n}^{-}$14), Mineração e Geologia (no 15), Contratações Públicas (no 16) e Serviços (no 17). As proposiçóes do $S G T$ no 3 quantitativamente foram as mais expressivas entre os SGTs na primeira década de funcionamento do Mercosul (gráfico 1).

GRÁFICO 1

Mercosul: regulamentação técnica nas resoluçães do GMC (1991-2016) $(\mathrm{Em} \%)$

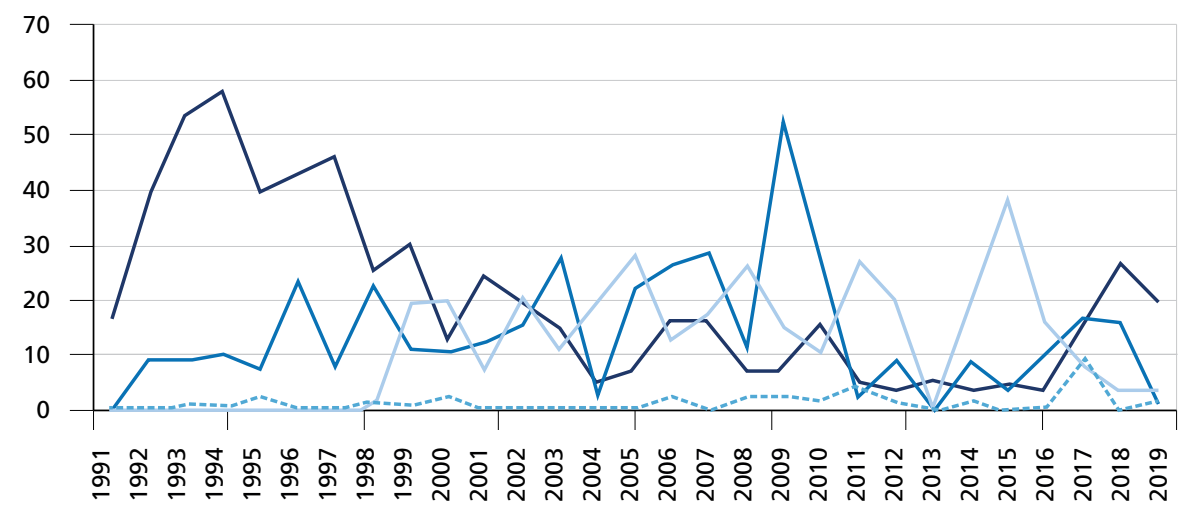

- SGT no 3 SGT no 8 SGT no 11 ----- Outros

Elaboração do autor.

O gráfico 1 mostra a participação dos três principais SGTs mais atuantes sobre os temas regulamentos técnicos e normas técnicas, os SGTs n오 3,8 e 11 , nas resoluçóes do GMC. ${ }^{9} \mathrm{O}$ agrupamento outros é o somatório do SGT no 5 (Transportes) com o SGT no 7 (Indústria).

9. Os percentuais são calculados pela relação entre a quantidade de reuniões do GMC em que se tratou de algum assunto relativo a regulamento técnico e norma técnica provenientes dos SGTs selecionados sobre o total de reuniões do GMC. 
Dos dezoito SGTs, ao menos dezesseis têm competência sobre o tema da regulamentação técnica. Os de maior atuaçấo na área são o SGT no 3 (Regulamentos Técnicos e Avaliação da Conformidade), o SGT no 8 (Agricultura) e SGT no 11 (Saúde). ${ }^{10}$

Na primeira década de vida do Mercosul, de 1991 a 2001, o SGT no 3 e o SGT no 8 , em conjunto, levaram questōes de interesse para a temática de regulamentos e normas técnicas a 51\% das reuniōes do GMC. De 1999 a 2016, o SGT no 3 respondeu, da presença do tema regulamentos e normas técnicas nas decisões do GMC, por 13\%; o SGT no 8, por $17 \%$; e o SGT no 11 , por $20 \%$. A ascensão do tema saúde é diretamente relacionada com a criação, em 1999, da Agência Brasileira de Vigilância Sanitária (Anvisa), ${ }^{11}$ revelando a importância das organizaçóes estruturadas para a condução das questôes regulatórias (Prado e Bertrand, 2015). Equivalem ao papel da Anvisa para o SGT no 11 o Instituto Nacional de Qualidade Industrial (Inmetro) e o Ministério da Agricultura, Pecuária e Abastecimento para o SGT no 3.

O período de 2017 a 2019 foi marcado pela organização e pela sistematização das atividades relativas à regulamentação técnica e à avaliação de conformidade. A aprovação pelo GMC de três normativas de procedimentos expressam, particularmente, os objetivos dos gestores de aperfeiçoamento institucional e organizacional: a Resolução Mercosul/GMC nº 45/2017 (procedimentos para elaboração, revisão e revogação de regulamentos técnicos e procedimentos do Mercosul de avaliação da conformidade ${ }^{12}$ - revogação da Resolução GMC nº 56/2002); a Resoluçáo Mercosul/GMC no 57/2018 (glossário de termos relativos a regulamentos técnicos e avaliação da conformidade - revogação da Resolução GMC no 24/2003); e a aprovação pelo CMC do Acordo de Boas

\footnotetext{
10. As resoluções do GMC relativas ao SGT no 3 são praticamente todas afins à temática da Resolução no 45/2017, enquanto as do SGT no 11, não necessariamente. Numericamente, o SGT no 10 teria menor incidência na matéria, mas há situações que fogem a essa previsão. Como no caso da Norma Regulamentadora no 12 (Segurança no Trabalho em Máquinas e Equipamentos), da Portaria do Ministério do Trabalho no 3.214, de 8 de junho de 1978, alterada por dezesseis portarias, cinco notas técnicas e uma instrução normativa. A penúltima alteração mais recente é por portaria de 15 de maio de 2018. 0 primeiro artigo dessa norma explica a alteração: "Esta norma regulamentadora e seus anexos definem referências técnicas, princípios fundamentais e medidas de proteção para garantir a saúde e a integridade física dos trabalhadores e estabelece requisitos mínimos para a prevenção de acidentes e doenças do trabalho nas fases de projeto e de utilização de máquinas e equipamentos de todos os tipos, e ainda à sua fabricação, importação, comercialização, exposição e cessão a qualquer título, em todas as atividades econômicas, sem prejuízo da observância do disposto nas demais normas regulamentadoras aprovadas pela Portaria no 3.214, de 8 de junho de 1978, nas normas técnicas oficiais e, na ausência ou omissão destas, nas normas internacionais aplicáveis" (grifo nosso). Disponível em: <https://www.legisweb.com.br/legislacao/?id=248187>.

11. A Anvisa foi criada pela Medida Provisória № 1.791, convertida na Lei o 9.782, publicada em 26 de janeiro de 1999. 12. A resolução traz definições que determinam seu escopo, entre elas duas que são específicas ao Mercosul: i) Regulamento Técnico Mercosul (RTM): regulamento técnico harmonizado pelos Estados-partes e aprovado pelo GMC por meio de resolução; e ii) Procedimento Mercosul de Avaliação de Conformidade (PMAC): procedimento de avaliação de conformidade harmonizado pelos Estados-partes e aprovado pelo GCM por meio de resolução. Exemplos de regulamentos técnicos regionais.
} 
Práticas Regulatórias e Coerência Regulatória do Mercosul (Decisão Mercosul/CMC no 20/2018).

As iniciativas relatadas não apenas revelam a disposição de modernização gerencial e institucional, mas também o interesse de convergência para os padróes internacionais. $\mathrm{O}$ recurso ao apoio de instituiçóes especializadas nacionais para a implementação de resoluções do GMC relativas a regulamentos técnicos também foi intensificado no período, o que encontra no SGT no 3 (Regulamentos Técnicos e Avaliação de Conformidade) o canal adequado. Esse cenário demandou o maior protagonismo do SGT no 3, que está refletido no gráfico 1, inclusive porque 2018 e 2019 são anos em que o número de resoluçóes do GMC (63 e 66, respectivamente) está acima da média do século (54).

Para melhor situar o cenário mostrado no gráfico 1, é importante observar que, embora as decisóes das instâncias superiores do Mercosul, como o GMC, pelas regras do acordo, devam ser internalizadas no arcabouço regulatório dos respectivos parceiros do bloco, foi necessário criar um grupo técnico especialmente para tratar de sua institucionalização doméstica (behind the border), o que é revelador de que isso não ocorre de modo linear e automático.

\section{MARCOS NA HARMONIZAÇÃO NORMATIVA TÉCNICA NO MERCOSUL}

Embora problemas de coordenação macroeconômica tenham sido mais negativamente impactantes para o processo de integração sub-regional, a harmonização dos regulamentos técnicos revelou-se um grande desafio para o Mercosul. A miríade de questóes microeconômicas, institucionais e técnicas, as repercussóes internas (behind the border) de ajustes regulatórios definidos no front externo, o impacto da inovação tecnológica e das alteraçôes institucionais por iniciativa do gestor público e do legislador em cada país fazem da almejada harmonização regulatória um verdadeiro "quebra-cabeça".

O pioneirismo do Mercosul com a uniāo aduaneira teve um custo. A viabilidade desse objetivo esbarra na heterogeneidade das IQs existentes nos países-parte do acordo. Porém, se limitada a capacidade de mobilização de recursos financeiros e técnicos, isso não elude a convergência institucional básica entre os países, refletida na similitude dos arranjos, envolvendo as funçóes públicas governamentais e privadas responsáveis pela regulamentação e normalização técnica em cada um deles.

Ao final de 1999, o acúmulo de pendências relacionadas à harmonização dos regulamentos técnicos a serem dirimidos no Mercosul, em um contexto de dificuldades de negociação agravadas pelos impactos das crises financeiras internacionais, com resultados comerciais intra e extrabloco pouco animadores, contribuiu para os questionamentos sobre a viabilidade do bloco tal qual 
inicialmente concebido. Ainda assim, o projeto Mercosul experimentou avanços institucionais importantes na perspectiva dos seus objetivos originários.

Em dezembro de 1999, foi aprovado o convênio com a AMN para o desenvolvimento da Norma Mercosul (NM).

Em fevereiro de 2002, deu-se a assinatura do Protocolo de Olivos, para entrar em vigor em janeiro de 2004 (Pena e Rozemberg, 2005), ${ }^{13}$ um avanço institucional do Mercosul bastante significativo, ao estabelecer um mecanismo de solução de controvérsias avançado para os padrōes internacionais (Arnold e Rittberger, 2013).

Em novembro de 1999, na cidade de Montevidéu, realizou-se a 36 a Reunião Ordinária do GMC, na qual foi analisada a proposta de convênio de cooperação entre o Mercosul e o Comitê de Normalização, e aprovou-se o Projeto de Decisão $\mathrm{n}^{\circ}$ 13/1999. ${ }^{14}$ A seguir, em 7 de dezembro do mesmo ano, em Montevidéu, o Conselho do Mercado Comum (CMC) autorizou o GMC a assinar o Convênio de Cooperação entre o Mercosul e a AMN. ${ }^{15}$ Esse ato configura ousado movimento realizado pela estrutura hierárquica do Mercosul, com vistas a criar condiçôes para a superação das dificuldades do bloco no tocante a regulamentos técnicos e normas técnicas.

A decisão do CMC deve ser avaliada segundo as óticas institucional e técnica, conforme se constata nos consideranda que embasaram a decisão do $\mathrm{CMC}$, ao referendar a supressão do Comitê Mercosul de Normalização pela Estrutura Orgânica do Mercosul - estabelecida pela Resolução GMC no 20/1995, no marco do Protocolo de Ouro Preto $-{ }^{16}$ e aprovar o convênio com a AMN, decisão essa balizada pelos motivos expressos nos arrazoados do convênio.

Os consideranda do convênio apontam a conveniência de "estabelecer uma cooperação entre os órgãos do Mercosul responsáveis por regulamentos técnicos e o organismo não governamental que reúna as entidades dos Estados-partes do Mercosul que se ocupam das normas técnicas"17 (Mercosul, 1999). A solução foi adotada para atender às necessidades técnicas alcançáveis a partir da integração dos entes reguladores com os organismos normalizadores.

A interação entre os entes responsáveis pelos RTMs e as entidades normalizadoras ("que se ocupam das normas técnicas") dos países do bloco tem fundamentação relevante. A norma técnica (standard), uma prescrição técnica

\footnotetext{
13. Ver também Mercosul (2002).

14. Ata Mercosul/GMC no 4/1999. Disponível em: <https://documentos.mercosur.int/public/reuniones/doc/552>.

15. Decisão Mercosul/CMC no 12/1999.

16. Decisão Mercosul/CMC no 12/1999.

17. AMN.
} 
conhecida por ser voluntária na sua elaboração e na sua adoção e utilização, é uma referência técnico-científica para o regulamento técnico. Ao ser incorporada ou "adotada" no regulamento técnico, essa norma técnica (support standard) passa a ter sua observância mandatória.

A norma técnica será condição para a obtenção de um certificado ou uma anuência, por exemplo, para se levar a mercado um bem ou serviço, se um regulamento técnico determinar sua observância. Diversa é a questão da responsabilidade pela observância da norma técnica, como em situaçôes de risco à saúde ou ao patrimônio, mesmo sem um ato específico do poder público.

GRÁFICO 2

Evolução dos fluxos comerciais do Mercosul e das NMs e NMs internacionais adotadas no Brasil (1994-2018)

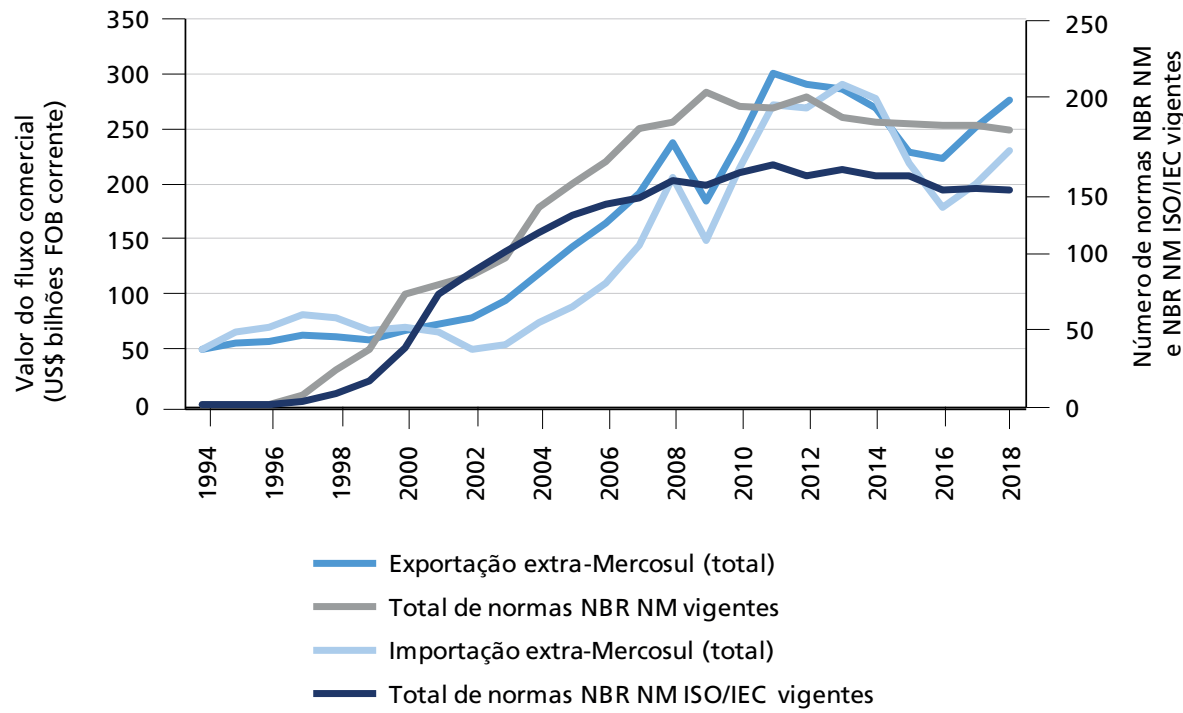

Fonte: Comtrade/United Nations Statistics Division (UNSD) e ABNT.

Elaboração de André Araújo Luchine, bolsista do Programa Nacional do Primeiro Emprego (PNPE) no Ipea.

Obs.: FOB - Free on Board; ISO - International Standard Organization.

O gráfico 2 oferece uma visão geral dos esforços de normalização do Mercosul ${ }^{18}$ vis-à-vis os fluxos comerciais (importação e exportação) do bloco para o total das mercadorias comercializadas.

As curvas NM e NM ISO/IEC, no gráfico 2, corroboram a percepção de que, na virada da década de 1990 e nos primeiros anos da década de 2000, o esforço de adoção de NMs acompanha o clima de otimismo com o Mercosul e

18. Normas NBR NM são as NMs internalizadas no Brasil pela ABNT. Normas NBR ISO/IEC são as NMs que adotam normas ISO ou normas IEC e são internalizadas no Brasil pela ABNT. 
seus objetivos originários. Esse esforço aparentemente avança mais na adoção das NMs que das NMs ISO/IEC. ${ }^{19}$

O gráfico 2 indica que, concomitantemente à estabilização da expansão do comércio extra-Mercosul na década de 2010, também o esforço de adoção de NMs arrefece. Se o esforço de adoção de NMs e NMs internacionais é um indicador de adesão aos objetivos fundadores do bloco, a partir de 2010 a 2012, quando se verifica estagnação da adoção de $\mathrm{NMs}$, os objetivos fundadores do bloco foram menos "prestigiados" ou outras alternativas entraram na agenda.

Avaliar se o resultado alcançado com o convênio com a AMN respondeu à expectativa e à necessidade de harmonização normativa e regulatória no Mercosul requer mais estudos. Parece que não foi suficiente, tanto assim que, em 2017, isto é, dezoito anos após o convênio, uma nova resolução do GMC (Resolução Mercosul/GMC no 45/2017) estabeleceu um conjunto de procedimentos com o intuito de tornar mais efetiva a harmonização normativa técnica no âmbito do Mercosul.

\section{A RESOLUÇÃO MERCOSUL/GMC № 45/2017}

A Resolução no 45 do GMC, de 2017, ${ }^{20}$ representa uma nova etapa na busca da harmonizaçấo dos regulamentos e normas técnicas no Mercosul. Ela aprova e traz no anexo um conjunto de critérios, entre os quais a fixação de conceitos e terminologia, a comunicação eletrônica entre os representantes nos subgrupos de trabalho e a estipulação de prazos para os procedimentos.

Os motivos determinantes da aprovação da Resolução no 45/2017 pelo GMC são essenciais para a compreensão do quadro geral em que se inserem esses aperfeiçoamentos processuais do Mercosul. O primeiro, o segundo, o terceiro e o quarto motivos foram, respectivamente, os seguintes.

Conferir maior agilidade aos procedimentos para elaboração, revisão e revogação de Regulamentos Técnicos Mercosul e Procedimentos Mercosul de Avaliação da Conformidade, considerando os avanços técnicos, cientificos e tecnológicos.

É conveniente para a inserção do Mercosul no mercado internacional tomar como base as normas, diretrizes e recomendaçôes internacionais de referência, na elaboração e revisão dos Regulamentos Técnicos Mercosul e Procedimentos Mercosul de Avaliação da Conformidade.

19. A adoção de normas técnicas comuns, mais ainda se internacionais, se justifica pela expectativa de eliminação de obstáculos ao comércio, por um lado, e, por outro, pela expectativa de ganhos de competitividade vis-à-vis mercados extrabloco. 0 gráfico 2 indica a possibilidade de um sentido causal ou pelo menos de estímulo da grande expansão do comércio na década de 2000 para a adoção de NMs, mas não o sentido causal inverso. Uma investigação nesta perspectiva requer outras informações e metodologia.

20. Revogação da Resolução GMC n 56/2002. 
É necessário tomar medidas para a proteção da vida ou da saúde animal ou vegetal, do meio ambiente, da defesa do consumidor ou para a prevençáo de práticas enganosas, nos níveis que se considerem apropriados, sempre que não se apliquem de forma a constituir barreiras técnicas ao comércio ou discriminação arbitrária ou injustificável ao comércio e que se baseiem em critérios técnicos e científicos.

Está vigente o Convênio de Cooperação entre o Mercosul e a Associação Mercosul de Normalização, assinado na cidade de Mendoza, em 20 de julho de 2017 (grifo nosso). ${ }^{21}$

Os dois primeiros motivos visam alinhar os procedimentos referentes a regulamentos e normas técnicas no âmbito do Mercosul a dois determinantes básicos da sua razão de ser enquanto objeto de interesse no bloco: o desenvolvimento científico e tecnológico e a competitividade e inserção internacional das economias dos países-parte do Mercosul.

O terceiro motivo responde à crescente emergência de novos temas a partir da questão da sustentabilidade socioambiental, tanto para garantir que sejam atendidas as demandas que essa temática coloca para os regulamentos e as normas técnicas como para que haja precaução, no sentido de que o seu atendimento não se constitua em barreiras injustificáveis ao comércio, seja por arbitrariedade ou dissonância com os critérios técnicos e científicos.

$\mathrm{O}$ quarto motivo reafirma o papel da $\mathrm{AMN}$ como agente viabilizador das diretivas da resolução, ampliando o alcance do seu comprometimento.

\section{CONSIDERAÇÕES FINAIS}

Regulamentos técnicos são empregados em políticas públicas para o atendimento de necessidades sociais, econômicas e ambientais. Sua importância como beneficiários e fatores de propulsão da globalização das atividades econômicas é essencial e tem crescido para o comércio e a integração econômica internacionais, como a que se verifica nas cadeias produtivas e de valor globais,

Regulamentos técnicos podem constituir BNTs ao comércio, e com a rebaixa tarifária das últimas décadas seu impacto tornou-se tão importante quanto o das tarifas alfandegárias. A eliminação do viés protecionista que pode assumir o regulamento técnico tem encontrado resposta nos acordos comerciais multilaterais da OMC, e nos acordos plurilaterais, bilaterais e regionais, cujas disciplinas seguem ou extrapolam aquelas da OMC. Em termos gerais, para evitar o viés protecionista que pode advir dos regulamentos técnicos, busca-se a harmonização regulatória entre os parceiros, mas o modo de se fazer isso varia muito.

21. Disponível em: <http://www.inmetro.gov.br/barreirastecnicas/pdf/acordos/RES_045-2017_Revogacao_revisao_e_ elaboracao_de_RTM_Mercosul.pdf>. 
Regulamentos técnicos são com frequência respaldados em normas técnicas (support standards). Normas técnicas são dotadas de conteúdo científico e tecnológico, são geradas na esfera empresarial, e sua utilização nas esferas produtivas e de circulação de bens e serviços é voluntária. Geradas na esfera empresarial, essas normas podem ser incorporadas a regulamentos técnicos, quando, então, passam a ser de observância mandatória.

Em um acordo comercial, o objetivo nacional é garantir a consistência do seu aparato regulatório e normativo comum às partes do acordo com os objetivos da sociedade e do sistema econômico, considerados seus interesses nacionais e internacionais. A convergência de interesses entre governo e setor privado deve ser buscada como estratégia para alcançar o objetivo nacional. A internacionalização das normas técnicas é um objetivo que deve ser compartilhado pelo governo e pelo setor privado. Busca-se, com isso, minimizar seu uso e do regulamento técnico como barreira ao comércio.

A maior experiência brasileira com harmonização regulatória é o Mercosul. A harmonização regulatória interna ao bloco é um objetivo a ser alcançado desde o primeiro ano de funcionamento de suas instituiçóes. Além das expectativas dos parceiros do Mercosul com respeito à harmonização regulatória intrabloco, a competitividade extrabloco também deve ser buscada por meio da harmonização regulatória - para isso, uma adequada estratégia de harmonização é necessária.

Dada a importância do Mercosul para o comércio e para as economias envolvidas, a internacionalização das normas técnicas como estratégia de harmonização regulatória entre os parceiros do Mercosul precisa ser profundamente avaliada e conduzida em uma cadência que atenda às possibilidades e aos interesses dos integrantes do bloco. Estão em questão as expectativas dos parceiros no acordo com relação à sua inserção internacional.

A experiência do Mercosul na harmonização regulatória é grande, pela própria quantidade e variedade de situaçóes que tiveram de ser enfrentadas nos trinta anos de existência do bloco. Lembrando que o esforço de harmonizaçáo regulatória técnica é basicamente de natureza setorial. Talvez um pouco ofuscado pelos impactos das instabilidades macroeconômicas que atingiram o bloco, o esforço despendido com a busca da harmonização dos regulamentos e normas técnicas não recebeu o tratamento analítico que merecia pela importância de que se reveste.

As instâncias governativas do Mercosul sempre procuraram responder aos desafios da harmonizaçấo regulatória. $\mathrm{O}$ agente público e o privado agindo em articulação quando assim requereram as situações - duas delas foram destacadas neste trabalho: o convênio com a AMN em 1999 e a Resolução Mercosul/GMC no 45/2017. 
Essas iniciativas, assim como a criação do tribunal arbitral permanente do Mercosul em 2002, por meio do Protocolo de Olivos, e muitas outras, revelam que, ao longo da sua existência, a perspectiva fundacional do bloco, de formação de uma área de livre comércio e união aduaneira, foi sempre referência de suas decisōes.

As linhas de explicação para os resultados da harmonização regulatória no âmbito dos regulamentos técnicos, aquém das mais altas expectativas, contemplam as seguintes causas.

1) As diferenças nas estruturas e nos sistemas institucionais de regulamentação técnica e do entorno de temas que isso envolve, como a avaliação de conformidade, resultante da evolução histórica pouco convergente das bases normativas, incluindo o estoque de normas técnicas, entre os parceiros do bloco.

2) O impacto da instabilidade macroeconômica nas economias do bloco e dos conflitos dos interesses setoriais, mais para a concorrência que para a complementaridade produtiva.

3) As instâncias diretivas do Mercosul promoveram aperfeiçoamentos processuais e adotaram medidas para a superação dos obstáculos à harmonização regulatória com perspectivas estratégicas como:

a) a instituição da NM (convênio com a AMN) com a orientação de sua internacionalizaçáo; e

b) a adoção da Resolução Mercosul/GMC no 45/2017.

O destaque para essas iniciativas não elide as inúmeras providências que, ao longo do tempo, foram adotadas para superar os desafios e fazer avançar a harmonização regulatória técnica no Mercosul.

Assim, para os anos vindouros do bloco, recomendam-se: i) o esforço conjunto das entidades regulamentadoras dos países, que é fundamental para a superação das diferenças normativas e regulatórias dos parceiros no bloco; e ii) uma melhor compreensão do papel e dos desafios da harmonização regulatória, essencial para planejar os esforços em prol dos objetivos do bloco.

\section{REFERÊNCIAS}

ARNOLD, C.; RITTBERGER, B. The legalization of dispute resolution in Mercosur. Journal of Politics in Latin America, v. 5, n. 3, p. 97-132, 2013. Disponível em: <https://doi.org/10.1177/1866802X1300500304>.

COSTA, A. V. Mercosul aos dez anos: crise de crescimento ou perda de identidade? Revista Brasileira de Política Internacional, v. 44, n. 1, jan./jun. 2001. Disponível em: <https://doi.org/10.1590/S0034-73292001000100004>. 
MERCOSUL - MERCADO COMUM DO SUL. Decisóes do Conselho do Mercado Comum, no 12/99. Montevidéu: Mercosul, 7 julho 1999. Disponível em: <http://www.sice.oas.org/Trade/MRCSRS/Decisions/dec1299p.asp>.

Protocolo de Olivos para a soluçáo de controvérsias no Mercosul. Olivos: Mercosul, 2002. Disponível em: <http://www.mercosul.gov.br/40normativa/tratados-e-protocolos/122-protocolo-de-olivos\#footer>.

PENA, C.; ROZEMBERG, R. Una aproximación al desarrollo institucional del Mercosur: sus fortalezas y debilidades. Buenos Aires: Intal; ITD, oct. 2005. Disponível em: <https://publications.iadb.org/es/publicacion/14943/unaaproximacion-al-desarrollo-institucional-del-mercosur-sus-fortalezas-y>.

PRADO, M. M.; BERTRAND, V. Regulatory cooperation in Latin America: the case of Mercosur. Law and Contemporary Problems, v. 78, n. 4, p. 205-230, 2015. Disponível em: <https://scholarship.law.duke.edu/lcp/vol78/iss4/9>.

THORSTENSEN, V. et al. Convergência regulatória na integraçáo comercial Brasil-Argentina: os impactos da regulação e da normalizaçáo técnica sobre o comércio internacional. Rio de Janeiro: Ipea, mar. 2019. (Texto para Discussão, n. 2454). Disponível em: <https://www.ipea.gov.br/portal/images/stories/PDFs/ TDs/td_2454.pdf>.

THORSTENSEN, V.; TIRONI, L. F. (Coord.). Regulatory coherence and convergence: a comparative analysis of Brazil, Argentina, Mexico, Colombia, and Chile - technical regulations and their supporting standards. São Paulo: FGV; WTO, 2019. Disponível em: <https://ccgi.fgv.br/sites/ccgi.fgv.br/files/ u5/E-book-CCGI-IPEA-CEPAL-2019-FinalTN2.pdf>.

\section{BIBLIOGRAFIA COMPLEMENTAR}

AZEVEDO, A. F. Z. Mercosur: ambitious policies, poor practices. Brazilian Journal of Political Economy, v. 24, n. 4 (96), p. 594-612, Oct./Dec. 2004. Disponível em: <https://www.scielo.br/pdf/rep/v24n4/1809-4538-rep-24-04-594.pdfs.

BID - BANCO INTERAMERICANO DE DESENVOLVIMENTO; INTAL INSTITUTO PARA A INTEGRAÇÃO DA AMÉRICA LATINA E O CARIBE. Informe Mercosul. Buenos Aires: BID; Intal, 2000.

ISO - INTERNATIONAL STANDARD ORGANIZATION. International classification for standards. 7th ed. [s.l.]: ISO, 2015. Disponível em: $<$ https://www.iso.org/files/live/sites/isoorg/files/archive/pdf/en/international_ classification_for_standards.pdf>. 
SELA - SISTEMA ECONÓMICO LATINOAMERICANO Y DEL CARIBE. Marcos regulatórios en los mecanismos de integración sub-regional en América Latina y el Caribe: armonización y convergência. Caracas: Sela, 2015. (XLI Reunión Ordinaria del Consejo Latinoamericano). Disponível em: <http://www.sela.org/es/centro-de-documentacion/base-de-datos-documental/ bdd/32627/marcos-regulatorios-en-los-mecanismos-de-integracion-subregionalen-alc-armonizacion-y-convergencia>.

VANGRASSTEK, C. Notifications, trade policy reviews and monitoring affecting trade. In: . The history and future of the World Trade Organization.

Geneva: WTO, 2013. Disponível em: <https://www.wto.org/english/res_e/ booksp_e/historywto_08_e.pdf>. 


\section{APÊNDICE}

TABELA A. 1

Presença da regulação técnica nas resoluções do Grupo Mercado Comum (GMC)

\begin{tabular}{|c|c|c|c|c|c|}
\hline & SGT $n=3$ & SGT $n=8$ & SGT no 11 & Outros (SGTs nos 5 e 7 ) & Total \\
\hline 1991 & 2 & 0 & 0 & 0 & 12 \\
\hline 1992 & 26 & 6 & 0 & 0 & 67 \\
\hline 1993 & 50 & 8 & 0 & 1 & 93 \\
\hline 1994 & 76 & 13 & 0 & 1 & 131 \\
\hline 1995 & 17 & 3 & 0 & 1 & 42 \\
\hline 1996 & 68 & 37 & 0 & 0 & 156 \\
\hline 1998 & 20 & 18 & 1 & 1 & 78 \\
\hline 1999 & 27 & 10 & 17 & 1 & 89 \\
\hline 2000 & 12 & 10 & 19 & 2 & 95 \\
\hline 2001 & 16 & 8 & 5 & 0 & 66 \\
\hline 2002 & 11 & 9 & 12 & 0 & 58 \\
\hline 2003 & 8 & 15 & 6 & 0 & 54 \\
\hline 2004 & 2 & 1 & 8 & 0 & 41 \\
\hline 2005 & 5 & 15 & 19 & 0 & 67 \\
\hline 2006 & 12 & 19 & 9 & 2 & 72 \\
\hline 2007 & 9 & 16 & 10 & 0 & 56 \\
\hline 2008 & 5 & 8 & 19 & 2 & 72 \\
\hline 2009 & 3 & 21 & 6 & 1 & 40 \\
\hline 2010 & 9 & 14 & 6 & 1 & 58 \\
\hline 2011 & 2 & 1 & 11 & 2 & 41 \\
\hline 2012 & 2 & 5 & 11 & 1 & 54 \\
\hline 2013 & 1 & 0 & 0 & 0 & 18 \\
\hline 2014 & 0 & 12 & 9 & 4 & 58 \\
\hline 2015 & 3 & 2 & 23 & 0 & 60 \\
\hline 2016 & 1 & 3 & 5 & 0 & 31 \\
\hline 2017 & 7 & 8 & 4 & 4 & 48 \\
\hline 2018 & 17 & 10 & 2 & 2 & 63 \\
\hline 2019 & 13 & 1 & 2 & 1 & 66 \\
\hline
\end{tabular}

Fonte: Mercado Comum do Sul (Mercosul).

Elaboração do autor.

Obs.: SGT - subgrupo de trabalho. 
